\title{
Research on Initiative Turnover Rate of the Post-90s Workforce-Taking Labor-Intensive Enterprises as an Example
}

\author{
Penglin Li, Hanglu Lu \\ School of Management, Xi'an University of Science and Technology, Xi'an, China \\ Email: Ipl@vip.163.com
}

Received 20 January 2014; revised 24 February 2014; accepted 4 March 2014

Copyright $(\subseteq 2014$ by authors and Scientific Research Publishing Inc.

This work is licensed under the Creative Commons Attribution International License (CC BY). http://creativecommons.org/licenses/by/4.0/

(c) (i) Open Access

\begin{abstract}
Based on the investigation of the traditional research on the factors which affect employee turnover rate, this paper aims at establishing a dynamic model of the post-90s workforce to explain the phenomenon of continuously high employee turnover rate of the post-90s workforce in labor-intensive enterprises. The model has explored the intervening factors of employee turnover and provided theoretical guidelines for companies to take actions against high turnover rate. The incentives for the post-90s employee initiative turnover have been probed thoroughly from the three aspects of employee, company and society and thus the managerial tactics have been proposed for companies to manage high turnover rate of employees. These tactics include mental health education, employee ethics education, improvement of working environments, rebuilding corporate culture, transforming employee management style, enhancing employee career planning management and setting up keep-to-the-point incentive mechanism, etc.
\end{abstract}

\section{Keywords}

The Post-90s Employees; Enterprise Turnover Intervention; Dynamic Turnover Model; Turnover Management Tactics

\section{Introduction}

People who were born after 1990 (hereinafter abbreviated as post-90s) are a group of labors with a distinctive trait and large scale, concentrating on labor-intensive enterprises. In the age of the late adolescence and early career, they are now facing the pressure of job, life, and marriage, which results in high turnover rate and large loss, not only a waste of corporate investment in human capital, but also a shortage of enterprise talents, which 
triggers the crisis of corporate human resources, and even endangers the enterprise survival and affects social stability. Therefore, study of initiative turnover of post-90s takes important theoretical value and practical significance.

\section{Theory on Employees' Turnover}

\subsection{Study of Employees' Turnover Intention}

Turnover intention is the intention to leave the organization the employees show after they work for a period in a place and take into consideration the gap between their needs and reality of that in all aspects. Scholars in abroad have done a great deal of researches on factors affecting employee's turnover intention [1] and the main conclusions are as follows:

Zeffance attributes turnover intentions to four dimensions: external factors (labor market), the employees' individual characteristics (such as intelligence, ability, experience, gender, interests, age and tenure, etc.), institutional factors (such as working conditions, salary, participation in and supervision on organizational decisionmaking) and employees' reaction of their work (including job satisfaction, job involvement and job expectations, etc.) [2]. Quarles thinks factors influencing turnover intention can be attributed to five aspects: job-related factors, individual related factors, external factors, organizational commitment and job satisfaction [3]. Iverson divides it into four dimensions: individual factors (gender, full-time or part-time, work motivation and family relationship, etc.), work-related factors (such as self-control, support from partners and executives, risk of work, role ambiguity and conflict, distributive justice, etc.), external environmental factors (job opportunity) and factors related to employee themselves (job satisfaction and organizational commitment, etc.) [4].

By studying the comprehensive model of the internal and external reasons affecting the employees' turnover in high-tech enterprises, Wang Yuqin and Ye Rensun proposed that the intention and external environment are the leading factors for employees' turnover [5]. Fu Yiqun Ling Wenqing, Fang Liluo attribute it into six dimensions: individual factors, work-related factors, organizational characteristics, personal adaptability in organizations, external factors, and other psychological factors like attitudes [6]. Liu Ying, Lin Qingdong, and Ling Wenqing put it into three dimensions: factors related to the staff, the organization and the society [7].

From the above researches, it can be concluded that factors affecting the employees' turnover intention are mainly related to the social factors, organizational factors and staff factors. Social factors include the level of economic development, employment policy, social security policy, labor supply and demand conditions; organizational factors are like corporate culture, job characteristics, payroll system, management, training, support, and interpersonal relationship; and staff factors include intelligence, skills, experience, gender, interest, age, and expectation, etc.

\subsection{Evolution of the Employees' Initiative Turnover Model}

The turnover is the process an individual terminates his relationship with the organization from which he obtains the material benefits [8]. It can be either initiative or non-initiative. The present turnover research mainly concerns the former one. Construction of the employees' initiative turnover model has been the focus of theoretical study of turnover. The traditional influential turnover models are the causality model by Prire [9] and Mueller [10], the intermediary chain model by Mobley [11], and the "tip mutation” model by Sheridan and Abelson [12]. They concluded in this way: take the staff expected working conditions, environmental characteristics, as well as the individual characteristics as antecedent variables affecting the turnover intention, job satisfaction and organizational commitment as intermediate variables between the antecedent variables and turnover intention, and by constantly enriching mediating variable settings explain the employees' psychological change in the decision-making process of turnover.

Since there are constantly new theories applied to the model in the research, new theories are successively applied to the turnover study based on the traditional expected theory, such as the retreat cognitive theory by Hom and Griffcth [13], and the image theory by Bcach [14]. Since 1990s, Lee and Mitchell have researched the turnover model from many ways, a significant breakthrough compared to the traditional model [15]. They introduced many concepts such as "system shock" and "job embeddedness" and explained from four aspects the motivation of the employees' retention or turnover decisions. Empirical studies have shown that the new model can better classify and interpret turnover [16]. Domestic researchers use this model to discuss employees' turnover 
problems in the science and technology enterprises, and have achieved a lot in digging the reasons for professional technical staffs.

\subsection{Introduction of the Turnover Research}

Overall, the present turnover studies mainly focus on cause analysis of the employees' turnover by use of the model, look for the decisive factors from the external environment of the organization, management of the organization and individual characteristics, and investigate employees' psychological change in the process from the initial turnover intention to the final turnover behavior. But the whole study ignores the corporate intervention on employees' turnover, as well as the positive effect of the intervention for blocking the formation of turnover intention and reducing employees' initiative turnover rate. As a result, the present theory can not well explain the differences of the turnover rate for post-90s employees in different enterprises in the same industry and same place. And it is difficult to theoretically provide effective means and measures to solve the initiative turnover problem of the post-90s employees for the enterprises.

\section{Whole Features of Post-90s Employees}

\subsection{Definition of "Post-90s Employees"}

"Post-90s" refers to the generation of Chinese born among 1990-1999. "Post-90s employees" refers to post-90s workers directly or indirectly engaged in enterprises [17]. In accordance with the provisions that child labor is forbidden in China, by 2011, the maximum age of the post-90s employees are 21; the minimum age is 16; their birth time is among 1990-1995.

\subsection{Quantity of "Post-90s Employees"}

There were approximately 1296.6 million "post-90s" in 2011 in China, (see Table 1). 93.011 million students of 16 - 21 years old were receiving education in the school (see Table 2). Based on the above data, the number of post-90s employees in 2011 is approximately 36.649 million, accounting for $4.8 \%$ of national employment (764.2 million people) for the same period; in the future four years, 59.955 million college students are going to

Table 1. Statistical table of births from 1990-1995 unit: 10 thousand persons.

\begin{tabular}{ccc}
\hline Year of birth & Age & Births \\
\hline 1990 & 21 & 2367 \\
1991 & 20 & 2243 \\
1992 & 19 & 2106 \\
1993 & 18 & 2113 \\
1994 & 17 & 2091 \\
1995 & 16 & 2046 \\
Total & $/$ & 12,966 \\
\hline
\end{tabular}

Data sources: The main demographic data of China from 1949-2001.

Table 2. Statistical table of people receiving education in 2011 unit: 10 thousand persons.

\begin{tabular}{cccc}
\hline Education category & Enrollment & Students enrollment & School attendance \\
\hline College and university & 681.5 & 2308.5 & 2990 \\
Secondary vocational school & 808.9 & 2196.6 & 3005.5 \\
Senior high school & 850.8 & 2454.8 & 3305.6 \\
Total & 2341.2 & 6959.9 & 9301.1 \\
\hline
\end{tabular}

Data sources: The National Economic and Social Development Statistical Bulletin in 2011. 
graduate and walk into the community as post-90s employees. With the continuous enlargement of the scale of post-90s employees, they increasingly play an important role in China's economic development.

\subsection{Structure of Post-90s Employees}

Post-90s rural migrant worker is an important part of post-90s employee group. According to the 2011 China migrant workers survey and monitoring report released by National Bureau of Statistics, there were total 252.78 million rural migrant workers in 2011, including the migrant workers among the ages of 16 - 20 which account for $6.3 \%$ rural migrant workers reaches 15.925 million, and accounts for $43.45 \%$ of the total post-90s employees (36.649 million), which is an important part of the whole post-90 employees group.

\subsection{Industry Distribution of Post-90s Employees}

Post-90s employees generally received junior middle school, secondary technical school or equivalent education; however, comparing with urban workforce, their educational level and skill level is still at a lower level, lacking of professional knowledge and expertise. Therefore, their employment scope is mainly concentrated in laborintensive industries in the secondary and tertiary industries, including manufacturing, construction, catering, electronics, textiles, clothing, footwear, plastics, and toys industries, among which manufacturing industry accumulates the most post-90s employees.

\subsection{Occupational Qualities of Post-90s Employees}

1) Cultural education situation. With the development of the nine-year compulsory education and vocational education, more post-90s employees have the opportunity to access into schools to receive education and improve cultural knowledge level. According to our current education system and post-90s employees' age structure, post-90s employees' qualifications are mainly concentrated in junior middle school, secondary technical school or equivalent education level, and they had not received higher education.

2) Vocational education situation. Post-90s employees with elementary school, junior middle school education level have not yet received the systemic vocational education, lack of expertise, and their vocational skills level is low. Post-90s employees with secondary technical school or equivalent education although have received secondary vocational education, but they are restricted by the level of China's vocational education, that is, moral education is lacked, mental health education is weak, skill cultivation level is low, their professional ethics is weak, they are lack of mental health knowledge and their skill level are low and uneven.

\subsection{Social Relations of Post-90s Employees}

Post-90s employees are in the early stage of their career; their job is unstable; they have a high turnover rate; their liquidity is frequent; they have no fixed abode, it is difficult to develop and maintain a stable relationship among colleagues, friends, and leaderships for them. Since they are away from family and friends, their original social relations support are gradually weakened. Therefore, social relation of post-90s employees is in a temporary shortage state; they lack of social support channel of talk, exchange thought and being cared.

\subsection{Living Environment of Post-90s Employees}

As for Labor-intensive industries, workers are intensive and living environment is poor. The majority of post90s employees live in dormitories, rental, and living conditions are relatively poor; living space is crowded and repressed. Take industry as example, workplace manufacturing, construction, mining industry is relatively fixed, some enterprises provide dormitories for employees, with water, electricity, warm .etc basic living conditions in them, however, the accommodation arrangements are compact and crowded and living space is cramped. As for services industry, due to the broad scope of practice, unfixed working hours, employees choose to live in urban fringe and share living with others which has convenient transportation, cheap rent, but living space is repressed.

\subsection{Physiological, Psychological and Behavioral Characteristics of Post-90s Employees}

1) Physiological characteristics of post-90s employees. Post-90s employees are in the late adolescence, which is a period of a child to early adulthood, rapid transition, physical growth towards mature and sexually mature. 
The development of the brain causes the significant progress in cognitive ability. Adolescent brain development behavior are: excessive gray substance of the brain in adolescence stage will be trimmed in the rate of $1 \%-2 \%$ per year and growing neurons (nervous system cells) and the connection among them becomes increasingly complex and rich make thinking more and more complex; increasing of myelin-the process that neuron cell is surrounded by fat cell-makes neural information transmission more efficient; significant development of regions is the prefrontal which enables people to think, evaluate and make complex decisions in a unique way, its development may lead to the progressive development of fine intelligence. Trimming of gray substance and continues increasing of neurons and myelin and significant development of prefrontal play an important role in development of adolescent cognition and thinking ability [18].

2) Psychological characteristics of post-90s employees. Post-90s employees are psychological sensitive, their mood changes rapidly; they are easy to be anger and impulses, which has a close relationship with adolescent physical development. With the rapid growth of height and weight, the pituitary signals stimulate other glands in the body, secreting adult levels of sex hormone and growth hormone and these growth hormone and sex hormone promote rapid growth and development, while higher hormone level may lead to emotional fast change and extremely sensitive psychological reactions. At the same time, responsible for the impulse control, brain areas of forehead leaf develops completely, the ability to control impulses is also not formed, this immature brain development likely to lead to dangerous and impulsive behavior which has adolescent characteristics, and even more extreme behavior may appear [18].

3) Behavioral characteristics of the post-90 employees. Post-90s employees are self-centered, critical to others and publicize themselves, which are notable feature of adolescent egocentrism. With the development of complex meta-cognitive, youth can have a deeper introspection and self-awareness and these two characteristics will lead to high degree of self-centeredness. Adolescent egocentrism is the status of self-absorption; they think that the whole world is paying attention to them; being self-centered and adolescent at the same time, they are full of the spirit of criticism to authority, are not willing to accept the criticism, and easy to point out others' errors in behavior [18].

4) Demanding characteristics of post-90s employees. A large part of post-90s employees are born in one-child families, they have a favorable life conditions, and they are at the intersection of late puberty and early career stage; their demanding characteristics are complex in structure and level. From demanding structure point of view, on the one hand, they are in the early days of his career and have special demanding of friendship, care, attention, recognition, affirmation, growth, respect, independence, autonomy, self-expression, self-play. On the other hand, they are in a stage of loving and marriage, they need to communicate with the opposite sex, to be accepted, loved, and intimate contacted; their demanding have the characteristics of times, such as the electronic entertainment products (MP3, game consoles, digital cameras etc.), brand-name clothing, internet access and other significant consuming propensity.

5) Value characteristics of post-90s employees. a) With the development of China's market economy, competitive pressures and interest relationship are complex and changeable, so post-90 employees pay more attention to the real interests, pursue quality of life and like to live according to their own interest and way. b) With the development of Internet, the widespread use of mobile phones, especially popularity of mobile internet taking phone as the terminal, a massive information resources and autonomy creation network are provided for post-90 employees, which makes them vision-widened, well-informed, mentally-alerted, and pursue equal participation, freedom of expression and self-creation. c) With the continuous development of globalization, the western values continually clash with China traditional value, traditional moral values are weakened gradually, which makes post-90s pursue enjoyment, stimulation, and brand-name, evade struggle and ridicule simple. Because of the weak belief education in school and family, they are often in a confused spirit state and generally lack ideals and beliefs.

\subsection{Working Characteristics of Post-90s Employees}

1) Unclear career goals. Post-90 employees lack a clear career direction and goals, on one hand, they do not know what they can do, and they can not determine and identify their target positions in accordance with their expectations, interests, and hobbies. They are unable to determine vocational learning and development plans. On the other hand they don't know economic and industrial structure and social position structure, moreover, they do not know the specific requirements of the knowledge skills, experience, toward different positions, there 
is no clear industry whereabouts and job goals of employment, their employment are full of contingency and blindness.

2) High working expectations. Post-90 employees were born in one-child families; their life conditions are favorable and live a free and happy life. They have high expectations towards their work and hope have professional skill to earn more money through working and want to have more time to rest, entertainment and learn. They want opportunities to self-express and self-shots and to be endorsed by the managers, and want excellent accommodation and living condition.

3) Unbalanced capacity development. Physical and mental development of post-90s employees is basically mature; they are energetic and agile; have flexible thinking, good memory, and strong ability to imitate. After the systematic skills training, they are able to quickly grasp the business knowledge and skills to meet the position needs in a short term, and being qualified to the task. They relatively lack of interpersonal communication skills, emotional management capacity, pressure regulating ability, conflict resolution capacity, wages disposable capacity and self-care ability, which results in their interpersonal relationships and mental health problems.

4) Un-strong working responsibility. Post-90s employees are self-centered, pursue their own comfort and freedom, lack of responsibility and professionalism to work, lack of love to work, especially lack of rigorous work attitude. In the course of their work, due to lack of concentration, negligence and un-strict implementation of operating procedures, operational errors, wrong materials using, quality issues, safety accidents frequently occur, many of which are major security incidents and quality accident.

5) Belonging sense missing. Post-90s employees engage in operation working in the grass-roots level of labor-intensive enterprises, they experience boring job content, long working hours, monotonous work, poor working conditions, lack cultural and recreational life, and they are under heavy work pressure; they experience mental and physical exhaustion, lack of care, recognition and praise from the enterprise support; they are difficult to approve and rely on corporate and corporate culture; they are full of the sense of loss to their enterprises; it is difficult to produce a sense of dependence and a sense of belonging to enterprise for them.

6) Low enterprise loyalty. Workforce became a commodity; it has the nature of pursuing benefits and can maximize the own value through free exchange in the market, which has become a widely accepted talent concept. Workface market mechanisms, however, have a serious impact on the traditional concept of "Take plant as house; my honor prospers with plant" so that employees become more and more indifferent with enterprise loyalty. Post-90s employees change their jobs frequently, which seems to be a normal and natural thing; they generally lack the love to enterprise, ideology of enterprise loyalty; their feelings towards enterprise is weak; their corporate loyalty is very low; their first thought is to leave when encountering something goes wrong.

7) Extremely low job satisfaction. Post-90s employees pursue comfort, freedom, equality, love, performance and self-express, and they have a very high expectations towards their work, but in reality they do the dirtiest, most tired, most suffering and most monotonous work, what they earned has a big disparity with urban labor, coupling with lack of entertainment and cultural life, brutal and simple management of managers, they are full of loss and disgust towards work and their job satisfaction is low.

\section{Characteristics and Harms of Post-90s Employee's Initiative Turnover}

\subsection{Characteristics of Post-90s Employee's Initiative Turnover}

\subsubsection{High Initiative Turnover Rate}

1) Post-90s rural migrant workers have a very high liquidity which seriously affects the employee turnover rate of post-90s employees. According to China's rural migrant workers survey and monitoring report in 2011 released by National Bureau of Statistics: the total rural migrant workers reached 25.278 million people in 2011; about 22.7\% rural migrant workers engage in present work less than 1 year, 43.1\% less than $1-2$ years, 20.9\% less than 3 - 5 years, the rural migrant workers among 16 - 20 years old engaged in present work more than five years accounted for $1.3 \%$, which is far less than post-80s and post-70s rural migrant workers' proportion: $7.6 \%$, $22.3 \%$, which fully explains that post-90s rural migrant workers have a very low stability, a high turnover rate and strong liquidity. According to a new generation migrant workers survey data by the studies ministry of the East China Normal University shows that [19]: the average turnover rate is 0.11 years of those who change their job most frequently. They change their job almost every month; the lowest turnover rate is average of 2 years who change their job least frequently, that is, their longest working time in the same enterprise is no more than 2 years. Average flow time interval within three months accounted for 17.6\%; the interval among 3 months to 6 
months accounts for $47.3 \%$; the interval among 6 months to 9 months accounts for $18.6 \%$; the interval among 9 months to 12 accounts for $13.8 \%$; above data adequately shows that the new generation of migrant workers flows very frequently.

2) The author tracks company A in long-term, which is an electronic product manufacturing enterprises. Production workers account for $72.5 \%$ in company $\mathrm{A}$, and more than $90 \%$ operating positions rely on manual labor with boring job content, a single working manner, average 6.5 days weekly work time, more than 10 hours work time a day. 65 hours weekly working time or more is more than the national statutory working time standard and it is a typical labor-intensive enterprises. Post-90s employees' initiative turnover rate is much higher than post-70' and post-90s' initiative turnover rate of Company A. Company A recruited 113 workers of post-90s in 2011, 89 resign initiatively, and initiative turnover rate reaches $78.76 \%$, far higher than post-80s and post-70s' proportion of $21.67 \%$ and $17.14 \%$, see Table 3. (Because of involving corporate trade secrets, company A's real name is hidden, if necessary, it can be obtained from the author.)

\subsubsection{Initiative Turnover Fluctuates with Time}

Post-90s employees' initiative turnover peak generally appears within three months after recruiting. Take A company as example, 89 person choose initiative turnover in 2011, of which 68 resigned within the first three months, accounting for $76.40 \%$ of the number of post-90s employees' turnover (see Table 4). Two peaks of initiative separation within 3 months after recruitment appear; the first peak appears in 2 - 3 weeks after recruitment; the other appears in 4 - 8 weeks after recruitment.

\subsubsection{Initiative Turnover Manner Is in Group}

Post-90s employees' initiative turnover manner is in group, generally they are leaded by one or a few employees with influence or inciting force and then their classmates, fellow and roommates begin to leave one after another, giving rise to mass initiative turnover, however, individual initiative turn is less.

\subsection{Initiative Turnover Damage of Post-90s Employees}

\subsubsection{Increase Enterprise Operation Cost Greatly}

Employees' initiative turnover will inevitably result in direct costs and indirect costs loss; the direct costs loss includes turnover costs, vacancy costs, replacement costs and training costs; the indirect costs loss includes the

Table 3. Statistical table of turnover of enterprise A in 2011.

\begin{tabular}{cccccc}
\hline Sequence & Staff category & Position & Recruiting numbers & Initiative turnover number & Initiative turnover rate \\
\hline 1 & Post-90s & ordinary worker & 113 & 89 & $78.76 \%$ \\
2 & Post-80s & ordinary worker & 120 & 26 & $21.67 \%$ \\
3 & Post-70s & ordinary worker & 35 & 6 & $17.14 \%$ \\
\hline
\end{tabular}

Table 4. Turnover table of post-90s employees in 2011 of enterprise A.

\begin{tabular}{|c|c|c|c|c|}
\hline Sequence & Turnover number of whole year & Turnover time & Turnover number & Proportion \\
\hline 1 & 89 & Within 30 days & 35 & $39.33 \%$ \\
\hline 2 & 89 & 31 - 60 days & 21 & $23.60 \%$ \\
\hline 3 & 89 & 61 - 90 days & 12 & $13.48 \%$ \\
\hline 4 & 89 & 91 - 1230 days & 9 & $10.11 \%$ \\
\hline 5 & 89 & 121 - 150 days & 6 & $6.74 \%$ \\
\hline 6 & 89 & 151 - 180 days & 2 & $2.25 \%$ \\
\hline 7 & 89 & 181 - 360 days & 4 & $4.49 \%$ \\
\hline Total & / & / & 89 & $100.00 \%$ \\
\hline
\end{tabular}


productivity cost losses, human resources productivity losses and the cost of new employee productivity loss [20]. The loss of indirect costs caused by an ordinary worker' initiative turnover is not very serious, but the mass turnover of post-90s employees in a short term will result in an insufficiency of workers, machine halting to wait for workers and other serious problems, which has direct impact on the normal operations of enterprises, so the mass turnover of post-90s will caused enormous loss of indirect costs.

\subsubsection{Cause Employees' Psychological Fluctuations and Impact Enterprise Operation Order}

Post-90s employees' turnover is in mass, leading to rapid quantity reduction of workers in a short time, which not only causes employees' mass psychological fluctuations, disrupts production schedule, procurement plan, the materials plan, sales plan, personnel plan, and destructs the normal operation order of enterprises.

\subsubsection{Cause Talents Fault and Human Resource Crises}

Under the situation of "labor shortage" in China; labor supply is a serious problem; the shortage of production workers in labor-intensive enterprises is very serious, recruitment is very difficult; post-90s employees resign in mass quantity, which makes the worker shortage even worse, fault enterprise workers, triggers the crisis of corporate human resources and even endangers enterprise survival.

\section{Initiative Turnover Analysis of Post-90s Employees}

\subsection{Initiative Turnover Dynamic Model of Post-90s Employees}

The factors affecting employee turnover intention mainly include social factors, organizational factors and employee factors. Social factors include economic development level, employment policy, social security policy, workforce supply and demanding condition; organizational factors include enterprise culture, job characteristics, wage system, management manner, training support, interpersonal relationship; employee factors include intelligence, skills, experience, gender, interests, age, and expectations. Based on management practices, the writer proposes the turnover intervention factors, including improving and optimizing work environment, increasing wages, and reshaping the corporate culture, enhancing the quality of cadres, changing management mode, providing mental health help, introduction of career management, improvement of the incentive mechanism; based on this, the traditional turnover model is improved; post-90s employees initiative turnover dynamic model is constructed (Figure 1); and post-90s initiative turnover process is divided into four stages: working stage, working comprehensive evaluation stage, initiative turnover intention formation stage and initiative turnover behavior stage, this division provides operating space for the enterprises' implementation of turnover intervention. If enterprise obtain information of employees towards work in time, and evaluate, determine turnover intervention target, take targeted turnover interventions measures and block initiative turnover intention formation, they can effectively reduce the initiative turnover rate of post-90s.

\subsection{Strategy of Staff Level}

As mentioned before, post-90s employees are born in one-child family, along with the dramatic social transformation of China, grew up with the development and popularization of high-speed internet and globalization, they are now in the intersection point of late adolescence and career exploring stage, and they have distinct groups characteristics and brand of the times. Their psychological quality, ability level, view of value, the structure of demand, job expectations, sense of responsibility, a sense of belonging, corporate loyalty and work satisfaction, etc. are significantly different from what of the 80 employees and 90 employees, this significant group characteristics (Table 5) have an important impact on employees' initiative turnover.

Post-90s employees' career development goals are not clear, development of the working ability is uneven, work expectations are too high, their psychology is fragile, their social relations are lacked, sense of corporate belonging is missing, corporate loyalty is low, which all lead post-90s' initiative turnover.

\subsection{Strategy of Enterprise Level}

Although post-90 employees have received junior high school, technical school or equivalent education, but their educational level and the skill level are still low, the scope of their employment is mainly concentrated in labor-intensive industries of the secondary and tertiary industries; and manufacturing accumulate the most. 


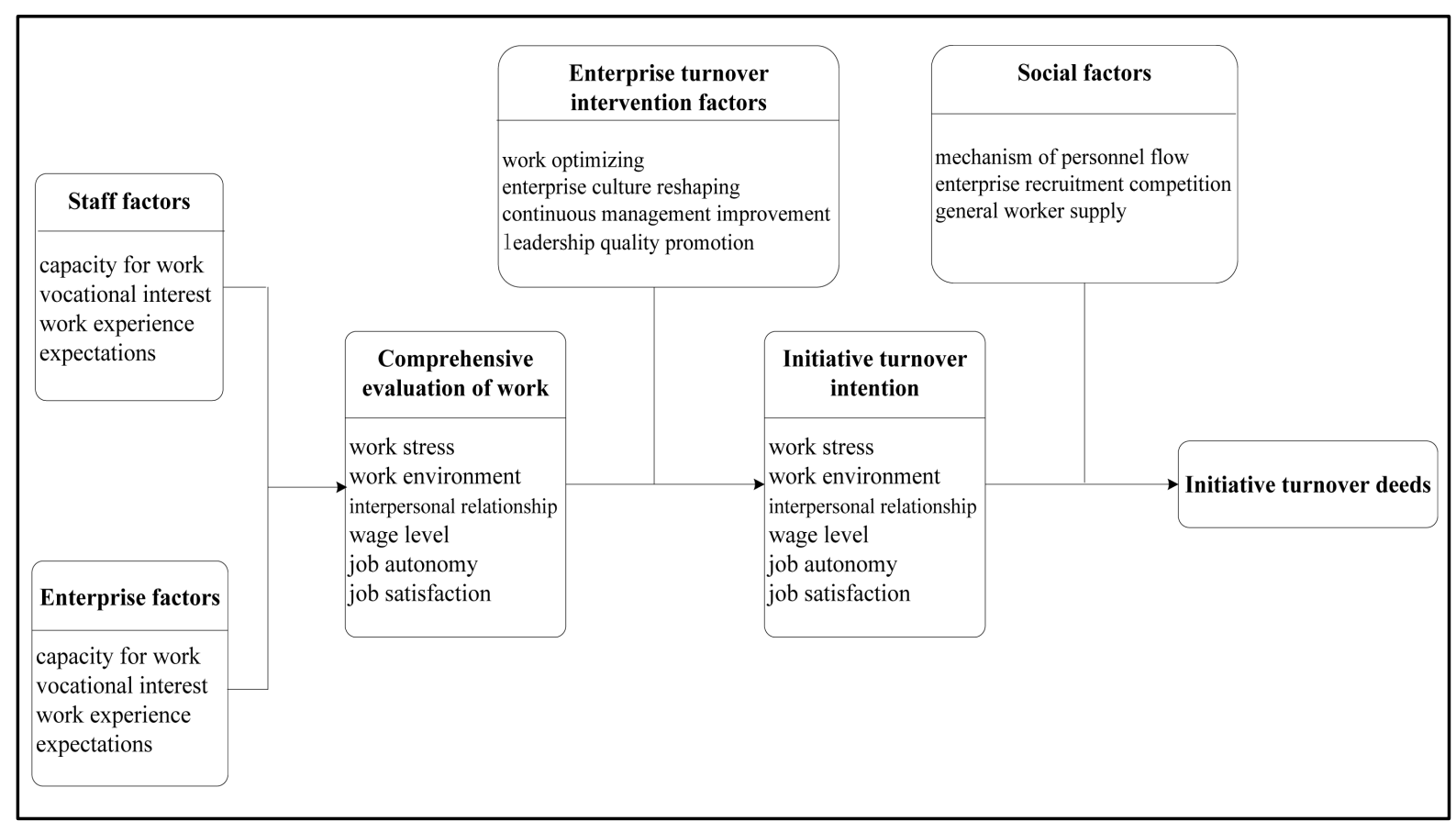

Figure 1. Dynamic model of post-90s initiative turnover.

\subsubsection{Work and Working Conditions}

Post-90s employees work on the grassroots operation jobs in labor-intensive enterprises, mainly manual labor, with a poor working conditions, long working hours, monotonous work content, and high labor intensity. a) Working conditions are poor. Labor-intensive enterprises have many problems in the work environment, such as noise, radiation, toxic substances, glass fiber, grinding dust, heat and humidity etc. which not only endanger the health of employees, but also are the major obstacle for employees to adapt to enterprise. b) Working time is long. They work five days a week, eight hours a day, working 40 hours a week, which is our current legal system of working hours. But the working hours of the most labor-intensive enterprises are far more than the statutory working time, which seriously consume the physical fitness of the employees, causing extreme physiological and psychological fatigue. c) Working content is dull. Positions of labor-intensive enterprises operating mainly manual labor work, employees repeat the same work in the same environment for a long time; they can not feel the fun and freedom of life, which easily lead to psychological attrition and aggravate frustration and disgust. d) Labor intensity is high. Many grassroots jobs in labor-intensive enterprises have physical requirements, plus the daily working time of about 10 hours and high working intensive, which may overdraft employees' energy.

\subsubsection{Enterprise Culture Analysis}

1) Lack of humanistic care. Labor-intensive enterprises' competitive advantage is cheap workforce; employees in the enterprises play a role of the "working tools"; tool features dominates; subjectivity of person has been ignored to a large extent; the interests of enterprises over-encroach the interests of employees and extrude life time of staff; corporate culture is cold and ruthless and lacks of care, resection, cherishing and support for employees.

2) Lack of cultural life. Restricted by characterizes and management levels of manual labor, main approach of labor-intensive enterprises to complete production tasks is working overtime; under the guidance of the core values, pursuing corporate profit maximization, close working arrangements, high-speed pace of work and endless overtime all encroaches the staff cultural life time, which leads to the shortage of employee culture life.

3) Lack of fairness. Most labor-intensive enterprises are not standardized in management; many enterprises adopt "rule of man" mode; bosses are the masters, and promotion of employees and wage adjustments are casual and often decouple with contribution responsibilities and skill level. Internal corporate lacks of fair and equity. 
Table 5. Comparison table of characteristics of post-90s, post-80s and post-70s.

\begin{tabular}{|c|c|c|c|c|}
\hline Comparison i & $\begin{array}{l}\text { Employee style } \\
\text { item }\end{array}$ & Post-70s & Post-80s & Post-90s \\
\hline \multirow{6}{*}{$\begin{array}{l}\text { Basic } \\
\text { situation }\end{array}$} & Date of birth & 1970-1979 year & 1980-1989 year & 1990-1995 year \\
\hline & Age level & 32 - 41 years old & 22 - 31 years old & 16 - 21 years old \\
\hline & Career Stage & Middle stage of career & Early stage of career & Exploration stage of career \\
\hline & Family role & Main strength of family & Most are married and have baby & Most are single \\
\hline & Family burden & Burden is heavy & Burden is relatively heavy & Burden is not heavy \\
\hline & Emotional state & Mature, stable, rational & Relatively mature, stable, emotion & Quick mood change \\
\hline \multirow{4}{*}{$\begin{array}{c}\text { Mental } \\
\text { characteristics }\end{array}$} & Pressure adjustment & $\begin{array}{l}\text { Self-adjustment, patience, } \\
\text { acceptance }\end{array}$ & Can self-adjust and release pressure & $\begin{array}{l}\text { Don't know how to } \\
\text { release pressure }\end{array}$ \\
\hline & $\begin{array}{l}\text { Interpersonal } \\
\text { communication }\end{array}$ & $\begin{array}{l}\text { Experienced and good } \\
\text { at communication }\end{array}$ & Can communicate smoothly & $\begin{array}{l}\text { Lack of experience and } \\
\text { have many hinders }\end{array}$ \\
\hline & $\begin{array}{c}\text { Characteristics } \\
\text { of demand }\end{array}$ & Emphasize wage and resection & High salary and in a good mood & $\begin{array}{c}\text { Emphasize mental feelings } \\
\text { and high salary }\end{array}$ \\
\hline & Values & Diligence, frugality, patience & $\begin{array}{l}\text { emphasize interest, } \\
\text { eager to be respected }\end{array}$ & $\begin{array}{l}\text { Equality, freedom, } \\
\text { and be comfort }\end{array}$ \\
\hline \multirow{8}{*}{$\begin{array}{c}\text { Working } \\
\text { characteristics }\end{array}$} & Working expectation & Safe, stable and high income & Higher wages, pleasant atmosphere & Easy, free, have the development \\
\hline & Career goal & Clear goal & $\begin{array}{l}\text { Clear goal, but have } \\
\text { some confusion }\end{array}$ & Unclear goal, confusion \\
\hline & Job responsibility & $\begin{array}{l}\text { Professional, responsible } \\
\text { and conscientious }\end{array}$ & $\begin{array}{l}\text { Responsible and relative } \\
\text { conscientious }\end{array}$ & $\begin{array}{c}\text { Weak sense of responsibility, } \\
\text { drifts along }\end{array}$ \\
\hline & Job involvement & Devoted and initiative & $\begin{array}{c}\text { Enthusiastic and relatively } \\
\text { initiative }\end{array}$ & $\begin{array}{l}\text { Lack of entrepreneur spirit } \\
\text { and devotion }\end{array}$ \\
\hline & Job satisfaction & Mostly satisfied & Relative satisfied and helpless & $\begin{array}{l}\text { Low degree of satisfaction } \\
\text { and full of disappointment }\end{array}$ \\
\hline & Enterprise belonging & $\begin{array}{l}\text { Have feeling and strong } \\
\text { sense of belonging }\end{array}$ & $\begin{array}{l}\text { Position and relatively } \\
\text { strong sense of belonging }\end{array}$ & $\begin{array}{l}\text { Lack of position and } \\
\text { sense of belonging }\end{array}$ \\
\hline & Enterprise loyalty & High loyalty & $\begin{array}{l}\text { Relative high loyalty and } \\
\text { quit sometimes }\end{array}$ & Lack of loyalty \\
\hline & Occupational stability & High stability & $\begin{array}{l}\text { Relative stability and } \\
\text { quit sometime }\end{array}$ & Poor stability and quit at any time \\
\hline
\end{tabular}

\subsubsection{Human Resource Management Analysis}

1) Personnel management is not standardized. There are many illegal problems in the area of personnel management in Labor-intensive enterprises, such as, working hours excesses of the statutory standards, overtime pay is not in accordance with the statutory standard, payment is defaulted, social insurance is unpaid, there is no system of annual vacation, labor contracts are ignored, labor protection products are insufficient and occupational disease examination is lacked.

2) Employee management mode is simple. Grass roots supervisor of labor-intensive enterprises are charged by senior staff, and they are experienced, proficient, have a strong sense of responsibility, but they are lack of the education and management knowledge, their management mode is simple, and mainly in requesting and commanding. Some supervisors even publicly abusive employees, which is easy to dampen the enthusiasm of the staff, resulting in employee psychological conflict and leading to strained relations between managers and employees.

3) Lack of psychological health education. Employees’ psychological health education in China started rela- 
tively late. After the Foxconn employees' jumping events, several labor-intensive enterprises begun to introduce employees assistance of psychology (EAP) to provide psychological healthy education and psychological assistance, but generally, labor-intensive enterprises employees' psychological health education are missing.

4) Lack of career development and planning. Human resource management level of labor-intensive enterprises is generally low, employee career development and management is simply limited to knowledge and skills training; enterprises are lack of systematic employee career planning and management; employees training system is not sufficient to support the career development demand and it lacks of personnel incentives mechanism and career development channels.

5) Employee incentive mechanism is not perfect. Labor-intensive enterprises generally take wage as the main incentive; incentive mode is single, employee incentive is not combined with acknowledgement demand, honor demand, achievement demand, and career development demand effectively; they can incentive employees for a long time and in diversified style.

\subsection{Social Environment Factors Analysis}

\subsubsection{The Impact of Supply and Demand of Workforce in Market on}

As a commodity in the talent market, workforce is bound to be affected by the impact of supply and demand in market. Under the situation of nationwide "workforce shortage", a large number of employment opportunities appear in the market, but ordinary workers supply is in serious shortage, which accelerates post-90s employees' initiative turnover.

\subsubsection{The Impact of Enterprise Competition on Initiative Turnover}

Labor-intensive enterprises' core competitiveness is cheap workforce, that is, the ordinary worker. Under the situation of a serious shortage of ordinary workers, the enterprises continue to increase wages to attract more ordinary workers to meet their production needs; which objectively facilitated post-90s initiative turnover.

\section{Post-90s Employees' Initiative Turnover Management Strategy}

\subsection{Strategy of Staff Level}

\subsubsection{Carry out Psychological Health Education}

Proceed from the mental characters and real mental problem, hold mental healthy knowledge lecture, help staff realize these problems such as work pressure, international relationship, career development, Internet dependency and job burnout etc., guide staff how to cope with stress, manage mood, resolve interpersonal conflict, communicate effectively, face Accident Work Injury, help staff to improve coping capacity of mental quality and mental problem, foster and improve staff's mental capital. If condition allows, enterprises can buy EAP (employee assistance plan) service to provide professional mental welfare.

\subsubsection{Enforce Professional Ethics Education of Staff}

In the process of staff management and education, Set model or lead by outstanding staff, enforce to foster staff' professional ethics, love spirit of staff to enterprise and responsible attitude toward work, enforce their acknowledgement and independency to enterprise culture, foster staff's Enterprise belonging and loyalty.

\subsubsection{Make the Best Use of the Circumstances So As to Develop Informal Organization}

Establish informal organization such as "woodpecker group”, "golden idea group”, "film group”, "basketball team”, "Wei Chi group” and so on to provide platform for employees' autonomy and creativity. Informal organization takes autonomous management mode which is good for employee to participate in enterprises' management activities, develop good interpersonal relationship, and experience a strong sense of belonging and achievement, which plays an important role in guaranteeing staff's mental health.

\subsection{Strategies in Enterprise Level}

\subsubsection{Improve the Working Environment}

1) Improve the hard working environment.

The hard environmental improvement, such as lighting, ventilation, dust removal facilities, security facilities, 
can reduce the work pressure, improve the working comfort, and reduce employee initiative turnover rate; it has great significance. Working environment design of labor-intensive enterprise is easy to fall into the mistaken region: task-centered environment, that is, environmental design pursuits of clean and order, but lost the human caring and interactive elements, therefore, enterprises should pay attention to hard environmental improvement, create a comfortable, safe, sanitary, and clean work environment through the optimization of light, temperature, humidity, noise, color, items placement through the research on the nature of work, job content and psychology and physiological features.

2) Optimize the soft working environment.

Working design optimization can make employees get encouragement and a sense of achievement, thereby reducing the initiative turnover rate. Following three measures can be accepted for working design: job rotation, job enrichment and job enlargement. Job rotation, employees can feel the freshness of the work through job rotation, so they can acquire more skills, and get more understanding of different work and improve collaboration capabilities. Job enrichment, diversification of job content and responsibility level changes can enhance the participation of the employees into work, which is the longitudinal expansion of job. Job enlargement, job expansion can make employees to take on more tasks, which is the horizontal expansion of the job, and it will give employees a greater sense of accomplishment.

\subsubsection{Remodel Enterprise Culture}

1) Remodel a people-oriented enterprise culture. Enterprises have to attach importance on fundamental role of people in the process of management, adequately consider the employee's personality and individuality, respect, concern and care every employee; build a culture atmosphere of equality, friend, mutual assistance in the enterprise; pay attention to foster employee's professional ethics quality; improve employees' vocational ability and foster a people-oriented enterprise culture.

2) Improve leaders' management quality. Strengthen the leadership cadres; train leading cadres to take virtues as first, treat workers as people, respect, care for, train each employee, closely combine the enterprise development with employee training; train a large number of management and technical personnel with good ethics and innovation awareness, and promote the sustained and healthy development of the enterprise.

3) Actively carry out cultural activities. a) Hold enterprise culture activities, such as employee sports meeting, karaoke ok contest, photography contest, staff birthday party etc.; create a environment of self-expression, actively participation and help with each other, allowing employees to enjoy the entertainment and to be respected. b) Organize all kinds of knowledge contest, skill contest, experience exchange meeting, book reports meeting, case seminars and other activities to accelerate the cross-sector spreading, integration and innovation of knowledge; improve employees' knowledge attainment; foster a organizational culture of love learning. c) Start outstanding deeds report, model figures learning activities, seminars and other activities in organizations; train staff to have professional ethics of dedication, honesty and trustworthiness.

\subsubsection{Change Employees' Management Manner}

Strengthen the training of grassroots management quality; help them to properly understand the psychological characteristics of the post-90s employees, reflect the shortcomings of the previous command-style management, guide them to change the management style; focus on training employees' moral character and professional competence; give employees opportunity to involve in the management; give employee the space self-management; defuse employees' resentment to management and greater exert their initiative and creativity.

\subsubsection{Build Occupation Career Development System}

Concerning post-90s' low vocational ability, fragile psychology, communication skills, set a step-by-step career development goal and clarify their career development promotion channel and criteria; develop a set of training courses; provide vocational mentoring system; finish career development plan through on-the-job training and combine with full-time training; build employees' career development files; records and track the various stages of the employees' level of skills, psychological quality and development of professional qualities.

\subsubsection{Build Targeted Incentive Mechanism}

Concerning post-90s employees, from their demand characteristics and career development stage goal, based on refining enterprises' existing payment incentive mode, design incentive mechanism; increase emotional motiva- 
tion, respect motivation, example motivation, honor motivation and achievement motivation; actively explore the enterprise culture incentive mode; constantly improve the incentive system; combine long-term incentives with short-term incentive; in the incentive process fully consider the personality characteristics of incentives target; maximize avoid random incentive for leaders.

\section{Conclusions}

Post-90 employee is a special labor group; the quantity is large; and they are widely distributed among all walks of life due to the industry characteristics and difference of enterprise management mode. Post-90s employees have characteristics of complexity and diversity; this paper takes labor-intensive enterprises as an example to study the post-90s employee initiative turnover, proposes turnover intervening variables which affect initiative turnover of employees, constructs dynamic model of post-90s employees initiative turnover, provides theoretical guidance for enterprises, deep analyzes the reason of post-90s employees' initiative turnover from the staff level, the corporate level, the social level, and proposes enterprises turnover management strategy.

The drawback of this paper is that it is difficult to fully reflect a picture of post-90s employees' turnover, and the turnover intervention strategies mentioned has certain industry limitations. At the same time post-90s employees are growing and new joined employees have higher education level; their employment scopes are broader and the occupation is not limited to the operation, so the initiative turnover of post-90s employee is becoming increasingly complex, which needs continuing research by managers and researchers to put forward a more effective response.

\section{References}

[1] Mobley, W.H. (1977) Intermediate Linkages in the Relationship between Job Satisfaction and Employee Turnover. Journal of Applied Psychology, 62, 237-240. http://dx.doi.org/10.1037/0021-9010.62.2.237

[2] Zeffane, R.M. (1994) Understanding Employee Turnover: The Need for a Contingency Approach. International Journal of Manpower, 15, 22-38. http://dx.doi.org/10.1108/01437729410074182

[3] Quarles, R. (1994) An Empirical Examination of a Model of the Turnover Intentions of Information Systems Auditors. Journal of Applied Business Research, 10, 73-86.

[4] Iverson, R.D. (1999) An Event History Analysis of Employee Turnover: The Case of Hospital Employees in Australia. Human Resource Management Review, 4, 397-418. http://dx.doi.org/10.1016/S1053-4822(99)00027-3

[5] Wang, Y.Q. and Ye, R.S. (2000) An Analysis with Game Model on the Turnover of Enterprises' Employees. System Engineering Press, Beijing.

[6] Fu, Y.Q., Ling, W.Q. and Fang, L.L. (2002) An Analysis with Game Model on the Turnover of Enterprises' Employees. China Labor, 7, 23.

[7] Liu, Y., Lin, Q.D. and Ling, W.Q. (2006) Analyses and Suggestions of the Influencing Factor of the State-Owned Enterprise Employee Turnover Tendency. Jiangsu Commercial Forum, 4, 129.

[8] Mobley, W.H. (1982) Employee Turnover: Causes, Consequences, and Control. Addision Wesley Publishing Company, New York.

[9] Price, J.L. and Mueller, C.W. (1981) A Causal Model of Turnover for Nurses. Academy of Manatement Journal, 24, 543-565. http://dx.doi.org/10.2307/255574

[10] Price, J.L. (1977) The Study of Turnover. Iowa State University Press, Ames.

[11] Mobley, W.H. (1977) Intermediate Linkages in the Relationship between Job Satisfaction and Employee Turnover. Journal of Applied Psychology, 62, 238. http://dx.doi.org/10.1037/0021-9010.62.2.237

[12] Sheridan, J.E. and Ahelson, M.A. (1983) Cusp Catastrophe Model of Employee Turnover. Academy of Management Journal, 26, 418-436. http://dx.doi.org/10.2307/256254

[13] Hom, P.W. and Griffeth, R.W. (1991) Structural Equations Modeling Test of a Turnover Theory: Cross Seletional and Longitudinal Analyses. Journal of Applied Psychology, 76, 350-366. http://dx.doi.org/10.1037/0021-9010.76.3.350

[14] Beach, L.R. (1990) Image Theory: Decision Making, in Personal and Organizational Contexts. Wiley, New York.

[15] Lee, T.W. and Mitchell, T.R. (1994) An Alternative Approach: The Unfolding Model of Turnover. Academy of Management Review, 19, 51-89.

[16] Donnelly, D.P. and Quirin, J.J. (2006) An Extension of Lee and Mitchell’s Unfolding Model of Voluntary Turnover. Journal of Organizational Behavior, 27, 59-77. http://dx.doi.org/10.1002/job.367 
[17] Zheng, X.Y. (2010) Research on the Incentives of Post-90s Employees in China Labor-intensive Enterprise. Wuhan University of Science and Technology, Wu Han.

[18] Feldman, R.S. (2011) Developmental Psychology: Explore the Life Development Track. China Machine Press, Beijing.

[19] Fu, P. and Tang, Y.C. (2009) Inverted “U” Type Trajectory and New Generation of Rural Workers’ Social Mobility. Zhejiang Social Sciences, 12, 43.

[20] Zhou, Y. (2009) Enterprise Human Resources Turnover Cost and Control Strategy. Human Resource Management, 11, 128. 